Original Article

\title{
Immediate Postoperative Complications of Sellar Suprasellar Lesions Operated Via. Pterional Approach
}

\author{
Hamayun Tahir ${ }^{1}$, Zulfiqar Ali Shah², Naseer Hassan ${ }^{1}$, Muhammad Ayaz ${ }^{3}$, Mumtaz Ali ${ }^{4}$ \\ Farooq Azam ${ }^{5}$, Samina Feroz ${ }^{6}$ \\ ${ }^{1}$ Department of Neurosurgery Nowshera Medical College/Qazi Hussain Ahmed Medical Complex, MTI, \\ Nowshera, ${ }^{2}$ Medical Department of Neurosurgery, District Head Quarter Hospital Charssada \\ ${ }^{3}$ Department of Neurosurgery, Saidu Group of Teaching Hospitals, Swat, ${ }^{4}$ Department of Neurosurgery, \\ Peshawar Medical College/Prime Teaching Hospital, ${ }^{5}$ Department of Neurosurgery, Lady Reading \\ Hospital, ${ }^{6}$ Naseer Teaching Hospital, Peshawar, KPK - Pakistan
}

\begin{abstract}
Objective: In neurosurgical facilities, lesions that occur in the sella turcica and suprasellar area are frequently encountered. Different complications have been documented in the past studies following surgical management of sellar suprasellar lesions. This study's rationale was to get data from our local population on complications related to the transcranial approach for sellar suprasellar lesions. The study aimed to determine the immediate (within one week) postoperative complications of sellar suprasellar lesions operated via a pterional approach
\end{abstract}

Material and Methods: This descriptive case series study was conducted from June 2019 to June 2020 at the neurosurgical facility lady reading hospital Peshawar. A total of 117 patients, meeting inclusion criteria irrespective of gender, diagnosed with the sellar suprasellar lesion between 18 to 60 years of age operated through a pterional approach. Post-op patients were followed for seven days to access main outcome measures such as CSF leak and diabetes insipidus.

Results: CSF leak found in 7.7\% $(n=9)$ of patients while diabetes insipidus was detected in $14.5 \%(n=17)$ patients. Gender and age-based stratification showed no statistically significant difference for both postoperative complications.

Conclusion: Diabetes insipidus was a more frequent postoperative complication in patients undergoing the pterional approach for sellar suprasellar lesions followed by CSF leak. However, no statistically significant correlation was observed between different age groups and gender for all these complications.

Keywords: sellar lesions, CSF leak, diabetes insipidus, pterional surgery.

\section{Corresponding Author: Hamayun Tahir}

Department of Neurosurgery Nowshera Medical

College/Qazi Hussain Ahmed Medical Complex, MTI

Nowshera, KPK - Pakistan Email: hamayun_tahir@ymail.com

Date of Submission: 01-03-2021

Date of Revision: 09-09-2021
Date of Acceptance: 15-11-2021

Date of Online Publishing: 31-12-2021

Date of Print: 31-12-2021

DOI: DOI 10.36552/pjns.v25i4.514 


\section{INTRODUCTION}

The sellar suprasellar area lesions are deeply rooted and far closer to the anterior skull base's essential structures. Endoscopic endonasal procedures are widely practiced for such lesions nowadays; however, the transcranial approach is still commonly used and has numerous indications, mainly depending on tumor size, extension, and neurovascular structures involvement in the vicinity. ${ }^{12}$ The tumors that are approached transcranially are often large, contributing to severe consequences ${ }^{3}$. They may compress the optic pathways, squeeze or engulf the carotid arteries, induce hydrocephalus, and contribute to endocrine and hypothalamic dysfunction and even the frontal lobe functions are often altered by massive tumors extension to the frontal lobe. ${ }^{4-6}$

The aim of gross total resection of tumors in the sellar suprasellar region is to maintain and preserve normal functions and save patients' lives. The approach decision is made based on tumor size, location, extension, and configuration. Recent advances in exposure to cranial base, microsurgical procedures, neuroimaging, and neuronavigation have resulted in a greater extent of tumor resection and better surgical outcomes. ${ }^{7,8}$

The frontotemporal approach, also known as the pterional approach, is best known to many neurosurgeons because of its advantage of direct visual confirmation and easy accessibility to optic nerves, carotid arteries, pituitary gland, and stalk, tumor, and its relationship with sellar suprasellar structures. Furthermore, this technique provides several windows to the sellar suprasellar region once Sylvian fissure is being opened, such as prechiasmatic, trans-lamina terminal is, suprachiasmatic, between the optic nerve and internal carotid artery, lateral to and above internal carotid artery and its bifurcation, thus making it the most commonly used technique in neurosurgery nowadays. ${ }^{9,10}$
Despite the vast accessibility, familiarity, and flexibility of this approach, it is not without complications. A study on sellar suprasellar lesions operated transcranially via pterional approach reported transient Diabetes Mellitus in $23.4 \%$, meningitis in $13 \%$, panhypopituitarism in 6.3 , and CSF leak in $4.2 \%$ of cases. ${ }^{11}$ The literature review had shown many complications, including transient and permanent diabetes mellitus, CSF leak, Worsening of a visual deficit, temporary motor deficit, transient third nerve palsy, intracerebral hematoma, hydrocephalus, infection of CNS, Vasopasm and tearing of anterior circulation arteries, cavernous sinus injury, and panhypopituitarism, etc. in patients undergoing surgical resection for the sellar suprasellar lesion. ${ }^{12-14}$ Interestingly, all have reported the most common postoperative endocrinopathy was diabetes insipidus and CSF leak as main complication and variance in the incidence of other complications mentioned above. ${ }^{15}$ However, most of the literature on this topic is from different countries, and up to our knowledge, no work had been done so far on this topic in our local setup.

The rationale of this study was to look upon the most frequent immediate (within one week) and major complications following the pterional approach in patients with sellar suprasellar lesions. This study would show the magnitude of the patients undergoing the transcranial procedure for these lesions, and as it is the procedure of choice for most neurosurgeons operating upon such lesions. Hence, its complications are essential to study. Based on its results, we would suggest more research work and other recommendations to overwhelm these complications after a pterional approach for sellar suprasellar lesions. 


\section{MATERIALS AND METHODS}

\section{Study Design and Setting}

This descriptive case series study was conducted from June 2019 to June 2020 at the neurosurgical facility lady reading hospital Peshawar. A total of 117 patients, meeting inclusion criteria, sampled through non-consecutive probability sampling technique keeping the $26.7 \%{ }^{15}$ proportion of transient diabetes insipidus after surgery, 95\% confidence interval, and $8 \%$ margin of error, using WHO sample size calculator.

\section{Inclusion Criteria}

Patients of either gender between 18 to 60 years of age already diagnosed with sellar lesions (pituitary adenomas) $\geq 4 \mathrm{~cm}$ diameter, dumbbellshaped with large suprasellar extension that adheres intimately to optic nerves, carotids, or reaches the level of the third ventricle although situated in the direction of possible transsphenoidal route or parasellar lesions that do not enlarge Sella (meningiomas, craniopharyngiomas) with extension laterally into the cavernous sinus. Patients previously operated via endoscopic transsphenoidal techniques. Sellar/suprasellar lesions with ectatic (kissing) carotid arteries and fibrous tumors with suprasellar extension.

\section{Exclusion Criteria}

Redo cases. Patients having preoperative CSF leak. Patients with comorbid conditions such as uncontrolled diabetes mellitus and hypertension, chronic renal or liver failure, hematological diseases, or those unfit for general anesthesia administration.

\section{Data Collection}

Approval was obtained from the hospital's ethical and research committee before starting the study. A total of 117 patients meeting the inclusion criteria were enrolled in the study through OPD/ ER department in a consecutive manner. All patients were admitted to the neurosurgical ward for further evaluation. After taking a detailed history (onset of disease and its sign and symptoms), patients were subjected to detail physical, systemic, and neurological examination. The study's purpose and rationale were explained to the patients and informed written consent was obtained. All patients were operated on through a pterional approach by a neurosurgeon's team and gross total resection was achieved in all cases. And postoperative, all patients were followed closely for seven days. During their stay, they were accessed for Diabetes insipidus and CSF leak from the wound. In a pre-designed proforma, all critical information, including name, age, gender, address, and complications, was registered. To control confounders and bias in the study results, strict exclusion criteria were followed.

\section{Data Analysis}

All collected data were entered, processed, and analyzed using statistical software SPSS version 25. Descriptive statistics were applied to calculate mean \pm Standard deviation for quantitative variables such as age. Frequencies and percentages were used to express qualitative variables, i.e., gender, diabetes insipidus, and CSF leak. Immediate complications, e.g., diabetes insipidus and CSF leak within one week, were stratified among age and gender to see the effect modification. Post-stratification chi-square test was applied, keeping $p$-value $\leq 0.05$ as significant. The exclusion criteria were strictly followed to control confounders in the study.

\section{RESULTS}

\section{Gender and Age Distributions}

Out of a total of one hundred and seventeen ( $\mathrm{n}=$ 117) patients, $56.4 \%(n=66)$ of the patients were male with a mean age of 43.9 years \pm 9.5 SD, and 
43.6\% ( $n=51)$ of the patients were female with a mean age of 45.5 years $\pm 8.8 \mathrm{SD}$. The cumulative mean age was 44.6 years \pm 9.2 SD. $30.8 \%(n=36)$ of patients were between $18-40$ years and $69.2 \%$ $(n=81)$ between the age of 40 and 60 years.

\section{Incidence of Diabetes Insipidus and CSF Leak}

In our study sample, $14.5 \%(n=17)$ patients were diagnosed to have diabetes insipidus, and the incidence of CSF leak among studied subjects was $7.7 \%(n=9)$ in the first postoperative week.

\section{Stratification Based on Gender and Age}

Diabetes insipidus was found in $12.1 \%(n=8)$ males and $17.6 \%(n=9)$ for females. $p$-value through chi-square test was 0.400 , implicating no significant difference among both genders in diabetes insipidus occurrence. In the age group 18 - 40 years, diabetes insipidus was present in $19.4 \%(n=7)$ while the percentage was $12.3 \%$ $(n=10)$ in patients with the age group 40 to 60 years and the $p$-value through chi-square test was 0.315, reflecting that no substantial difference in the incidence of diabetes insipidus among the younger and older age group (see Table 1).

Table 1: Gender and Age-wise stratification for diabetes insipidus.

\begin{tabular}{|c|c|c|c|c|}
\hline \multirow{2}{*}{ Gender } & \multicolumn{2}{|c|}{ Diabetes Insipidus } & \multirow{2}{*}{ Total } & \multirow{2}{*}{$\begin{array}{c}\text { P-value after } \\
\text { chi-square Test }\end{array}$} \\
\hline & Present & Absent & & \\
\hline \multirow{2}{*}{ Male } & 8 & 58 & 66 & \multirow{6}{*}{$\begin{array}{c}0.400 \\
\text { (Insignificant } \\
\text { result) }\end{array}$} \\
\hline & $12.1 \%$ & $87.9 \%$ & $100 \%$ & \\
\hline \multirow{2}{*}{ Female } & 9 & 42 & 51 & \\
\hline & $17.6 \%$ & $82.4 \%$ & $100 \%$ & \\
\hline \multirow{2}{*}{ Total } & 17 & 100 & 117 & \\
\hline & $14.5 \%$ & $85.5 \%$ & $100 \%$ & \\
\hline Age & \multicolumn{2}{|c|}{ Diabetes Insipidus } & Total & P-value after \\
\hline Group & Present & Absent & Iotal & chi-square Test \\
\hline $18-40$ & 7 & 29 & 36 & \multirow{6}{*}{$\begin{array}{c}0.315 \\
\text { (Insignificant } \\
\text { result) }\end{array}$} \\
\hline Years & $19.4 \%$ & $80.6 \%$ & $100 \%$ & \\
\hline $40-60$ & 10 & 71 & 81 & \\
\hline Years & $12.3 \%$ & $87.7 \%$ & $100 \%$ & \\
\hline & 17 & 100 & 117 & \\
\hline Iotal & $14.5 \%$ & $85.5 \%$ & $100 \%$ & \\
\hline
\end{tabular}

http//www.pakjns.org
The CSF leak was 7.6 percent $(n=5)$ in males, while its percentage in females was 7.8 percent $(n=4)$. The $p$-value was 0.957 . CSF leak was observed in 2.8 percent $(n=1)$ in the age group 18 - 40 years, while the percentage was 9.9 percent $(n=8)$ in patients $41-60$ years of age. The P-value was 0.184, indicating no substantial difference between younger and older age groups in CSF leakage (see table 2).

Table 2: Gender and Age-wise stratification for CSF leak.

\begin{tabular}{llccc} 
Gender & \multicolumn{2}{c}{ CSF Leak } & Total & $\begin{array}{c}\text { P-value after } \\
\text { chi-square Test }\end{array}$ \\
Mresent & Absent & & 66 & \\
Male & 5 & 61 & 66 & 0.957 \\
& $7.6 \%$ & 92.45 & $100 \%$ & (Insignificant \\
Female & 4 & 47 & 51 & result) \\
& $7.8 \%$ & $92.2 \%$ & $100 \%$ & \\
Total & 9 & 108 & 117 & \\
& $7.7 \%$ & $92.3 \%$ & $100 \%$ & \\
\hline
\end{tabular}

\begin{tabular}{|c|c|c|c|c|}
\hline \multirow{2}{*}{$\begin{array}{l}\text { Age } \\
\text { Group }\end{array}$} & \multicolumn{2}{|c|}{ CSF Leak } & \multirow{2}{*}{ Total } & \multirow{2}{*}{$\begin{array}{l}\text { P-value after } \\
\text { chi-square Test }\end{array}$} \\
\hline & Present & Absent & & \\
\hline $18-40$ & 1 & 35 & 36 & \multirow{6}{*}{$\begin{array}{c}0.184 \\
\text { (Insignificant } \\
\text { result) }\end{array}$} \\
\hline Years & $2.8 \%$ & $97.2 \%$ & $100 \%$ & \\
\hline $40-60$ & 8 & 73 & 81 & \\
\hline Years & $9.9 \%$ & $90.1 \%$ & $100 \%$ & \\
\hline Total & 9 & 108 & 117 & \\
\hline & $7.7 \%$ & $92.3 \%$ & $100 \%$ & \\
\hline
\end{tabular}

\section{DISCUSSION}

Sellar suprasellar lesions are close to the anterior skull base critical neurovascular structures such as optic nerve and chiasm, pituitary stalk, and hypothalamus and can cause a wide range of clinical symptoms, e.g., visual deficits, polydipsia \& polyuria, acromegaly \& gigantism, amenorrhea $\&$ galactorrhea secondary to their mass effect and compression ${ }^{11}$. The most common tumors of the sellar suprasellar area are pituitary adenomas, craniopharyngiomas \& tuberculum sellae meningiomas, compromising 90 percent of all such tumors. ${ }^{16}$ The transcranial approach via 
pterional craniotomy is beneficial for surgical management of suprasellar and para sellar region tumors because it enables vital anatomical structures to be visualized in detail; whereas endoscopic transsphenoidal surgery is ideally suited for intrasellar tumors. ${ }^{17}$ Compared to other transcranial approaches, the key advantages of the pterional approach are flexibility, short distance, and direct route to the sellar suprasellar region along with minimal retraction of normal brain tissue. ${ }^{18}$ The extended pterional approach is the anterior extension of traditional keyhole pterional craniotomy and enables a broader operative field to resect extraventricular portions of a tumor through three surgical corridors; the optico-carotid triangle, lateral surgical window to the carotid artery, and triangle superior to the carotid artery bifurcation, while intraventricular portion can be removed through lamina terminalis. ${ }^{19,20}$ Besides, it is possible to combine a pterional approach with other surgical approaches. $^{21}$

This research demonstrated the magnitude of patients undergoing transcranial surgery for sellar suprasellar lesions and the presentation pattern of successive sequences of complications related to it in our local population. Our study examined the occurrence of diabetes insipidus and CSF leak as immediate (within one week) postoperative complications for these lesions following a pterional approach. The overall incidence of CSF leak among the total study population was $7.7 \%$ $(\mathrm{n}=9$ ), while diabetes insipidus was observed in $14.5 \%$ ( $n=17$ ). We further elaborated that CSF leak was less prevalent in males, i.e., $7.6 \%(n=5)$ as opposed to $7.8 \%(n=4)$ in females. Nevertheless, the findings were not statistically significant, i.e., the p-value was 0.957 . On the other hand, CSF leaks have been seen more often in patients over 40 years of age. In our sample, the incidence of diabetes insipidus was higher in females, i.e., $17.6 \%(n=9)$ than $12.1(n=8)$ in males with a $p$-value of 0.400 . Contrary to CSF leakage, diabetes insipidus has been identified more commonly in patients less than 40 years of age.

Several research evaluating surgical approaches to sellar suprasellar area lesions have demonstrated excellent outcomes with low morbidity and mortality rates. Our findings are similar to the data already published on the subject. In a recent report on giant sellar lesions, $46.75 \%$ of patients had transient diabetes insipidus, $37.3 \%$ had hypopituitarism, 1.33\% CSF leak, $4.07 \%$ intracranial hemorrhage, $3.25 \%$ intracranial infection..$^{22}$ In a retrospective review of 58 patients with tuberculum sellae meningiomas treated surgically, Mahmoud $M$ et al. demonstrated CSF leakage, as observed in $7 \%$ of patients, close to our study's findings. Besides, diabetes insipidus was lower than our study results, i.e., in 3 percent of patients, whereas, in our research, it was present in about 14 percent of patients. $^{23}$ In another study, Goel A and colleagues retrospectively examined surgical methods and findings for 70 patients treated with tuberculum sellae meningioma. In 8 percent of patients, CSF leak and diabetes insipidus were found in their study. The frequency of CSF leaks is almost close to our study results, according to their findings. ${ }^{24}$

In short, for a majority of sellar and suprasellar lesions, the pterional approach is favored. While this surgical method has grown out of favor for many decades, it has gained widespread use about half a century ago, as a large number of studies have shown outstanding surgical results with low morbidity and mortality rates ${ }^{25}$. Nevertheless, despite the long history of good results, many significant associated complications, ranging from immediate peri and postoperative medical to endocrine to surgical problems such as CSF leakage and diabetes insipidus incidence, remain a possible source. During pterional surgery, complications can be explained by several possibilities for procedural error in a limited anatomical space with unusual physiology and structural heterogeneity. In various studies, 
CSF leakage and diabetes insipidus following pterional surgery were documented, but the incidence of these complications in our local populations was not well known before; therefore, our study helped us collect data on this subject. The limitation of this research was that it was performed on a very small population with a tiny subset of postprocedural complications studied and analyzed.

\section{CONCLUSION}

Diabetes insipidus was a more frequent postoperative complication in patients undergoing the pterional approach for sellar suprasellar lesions followed by CSF leak. However, no statistically significant correlation was observed between different age groups and gender for all these complications.

\section{REFERENCES}

1. Zhao C, Chen Z, Xu N, Xue T, Wu X, You W, et al. Comparative analysis on microsurgical removal of craniopharyngioma via lateral supraorbital approach and standard pterional approach. Chinese Neurosurg J. 2018; 4: 16.

2. Tullos HJ, Conner AK, Baker CM, Briggs RG, Burks JD, Glenn CA, et al. Mini-Pterional Craniotomy for Resection of Parasellar Meningiomas. World Neurosurg. 2018; 117: e637-44.

3. Tamasauskas A, Bunevicius A, Matukevicius A, Radziunas A, Urbonas $M$, Deltuva V. Extended pterional approach for initial surgical management of craniopharyngiomas: a case series. Turk Neurosurg. 2014; 24 (2): 174-83.

4. Day JD. Surgical approaches to suprasellar and parasellar tumors. Neurosurg Clin N Am. 2003; 14 (1): 109-22.

5. Liu JK, Weiss MH, Couldwell WT. Surgical approaches to pituitary tumors. Neurosurg Clin N Am. 2003; 14 (1): 93-107.

6. Samandouras G, Kerr RSC, Milford CA. Minimally invasive biopsy of parasellar lesions: safety and clinical applications of the endoscopic, transnasal approach. Br J Neurosurg. 2005; 19 (4): 338-44.
7. Samii M, Gerganov VM. Surgery of extra-axial tumors of the cerebral base. Neurosurgery, 2008; 62 (6 Suppl. 3): 1153-8.

8. Aydin $\mathrm{IH}$, Takci $\mathrm{E}$, Kadioglu $\mathrm{HH}$, Kayaoglu $\mathrm{CR}$, Tüzün Y. Pitfalls in the pterional approach to the parasellar area (review). Minim Invasive Neurosurg. 1995; 38 (4): 146-52.

9. Figueiredo EG, Oliveira AMP, Plese JPP, Teixeira MJ. Perspective of the frontolateral craniotomies. Arq Neuropsiquiatr. 2010; 68 (3): 430-2.

10. Kim E, Delashaw Jr JB. Osteoplastic pterional craniotomy revisited. Operative Neurosurgery, 2011; 68 (suppl_1): ons125-9.

11. Liu H-C, Wu Z, Wang L, Xiao X-R, Li D, Jia W, et al. Frontolateral Approach Applied to Sellar Region Lesions: A Retrospective Study in 79 Patients. Chin Med J (Engl). 2016; 129 (13): 1558-64.

12. Pintea B, Mogyoros A, Andrasoni Z, Florian IS. Fronto-temporal approach in sellar and parasellar tumors. Romanian Neurosurgery, 2013; 15: 80-91.

13. Shi $X$, Wang Z. [Experience in surgical treatment of 110 patients with craniopharyngiomas]. Zhonghua Wai Ke Za Zhi. 2001; 39 (8): 608-10.

14. Zhang $Y$, Xu B, Jiang J, Feng $S$, Bu B, Zhou T, et al. [Treatment for giant pituitary adenomas through transcranial approach in a series of 112 consecutive patients]. Zhonghua Wai Ke Za Zhi. 2015; 53 (3): 197-201.

15. Li H-Y, Feng C-Y, Zhang C, Su J, Yuan J, Xie Y, et al. Microscopic surgery for pituitary adenomas to preserve the pituitary gland and stalk. Exp Ther Med. 2017; 13 (3): 1011-6.

16. Dusick JR, Fatemi N, Mattozo C, McArthur D, Cohan $P$, Wang $C$, et al. Pituitary function after endonasal surgery for nonadenomatous parasellar tumors: Rathke's cleft cysts, craniopharyngiomas, and meningiomas. Surg Neurol. 2008; 70 (5): 4812.

17. Komotar RJ, Roguski M, Bruce JN. Surgical management of craniopharyngiomas. J Neurooncol. 2009; 92 (3): 283-96.

18. Honegger J, Tatagiba M. Craniopharyngioma surgery. Pituitary, 2008; 11 (4): 361-73.

19. Elliott RE, Wisoff JH. Surgical management of giant pediatric craniopharyngiomas. J Neurosurg Pediatr PED. 6 (5): 403-16.

20. Wang K-C, Kim S-K, Choe G, Chi JG, Cho B-K. Growth patterns of craniopharyngioma in children: 
role of the diaphragm sellae and its surgical implication. Surg Neurol. 2002; 57 (1): 25-33.

21. Yaşargil MG, Curcic $M$, Kis $M$, Siegenthaler $G$, Teddy PJ, Roth P. Total removal of craniopharyngiomas. Approaches and long-term results in 144 patients. J Neurosurg. 1990; 73 (1): 3-11.

22. Deng HS, Ding ZQ, Zhang SF, Fa ZQ, Wang QH. Surgical therapeutic strategy for giant pituitary adenomas. Biomed Res. 2017; 28 (19): 8284-8.

23. Mahmoud M, Nader R, Al-Mefty O. Optic canal involvement in tuberculum sellae meningiomas: influence on approach, recurrence, and visual recovery. Neurosurgery, 2010; 67 (3 Suppl. Operative): ons108-18; Discussion Ons118-9.

24. Goel A, Muzumdar D, Desai KI. Tuberculum sellae meningioma: a report on management on the basis of a surgical experience with 70 patients. Neurosurgery, 2002; 51 (6): 1354-8.

25. Raza SM, Effendi ST, DeMonte F. Tuberculum Sellae Meningiomas: Evolving Surgical Strategies. Curr Surg Reports, 2014; 2 (11): 73.

\section{Additional Information}

Disclosures: Authors report no conflict of interest.

Ethical Review Board Approval: The study was conformed to the ethical review board requirements.

Human Subjects: Consent was obtained by all patients/participants in this study.

\section{Conflicts of Interest:}

In compliance with the ICMJE uniform disclosure form, all authors declare the following:

Financial Relationships: All authors have declared that they have no financial relationships at present or within the previous three years with any organizations that might have an interest in the submitted work.

Other Relationships: All authors have declared that there are no other relationships or activities that could appear to have influenced the submitted work.

\section{AUTHORS CONTRIBUTIONS}

\begin{tabular}{|l|l|l|}
\hline Sr.\# & Author's Full Name & Intellectual Contribution to Paper in Terms of: \\
\hline 1. & Hamayun Tahir & 1. $\quad$ Study design and methodology. \\
\hline 2. & Zulfiqar Ali Shah & 2. Paper writing, referencing, data calculations \\
\hline 3. & Naseer Hassan & 3. Data collection and calculations. \\
\hline 4. & Muhammad Ayaz & 4. Analysis of data and interpretation of results etc. \\
\hline 5. & Mumtaz Ali & 5. Literature review and manuscript writing. \\
\hline 6. & Farooq Azam & 6. Analysis of data and quality insurer. \\
\hline 7. & Samina Feroz & 7. Literature review and manuscript writing. \\
\hline
\end{tabular}

